plex phytodrug the sedative effect is associated with the presence of biologically active substances. Particularly, the effect was due to the triterpenic saponines, glicoside hesperedin and polysaccharides of linden leaves. Flavonoids of St John's wort herb possess antidepres- sive activity. Thus, hypericin "softly" inhibits monoamineoxydase and hyperforin supresses the capture of the serotonin, noradrenalin and dopamin, and also inhibits GABA. So the phytodrug is consistent with the effect of comparator agent.

\title{
UNCOMMON APPROACHES FOR NATURAL PRODUCTS ANALYSIS - CAPILLARY ELECTROPHORESIS AND CAPILLARY ELECTROCHROMATOGRAPHY
}

\section{Ganzera Markus}

Institute of Pharmacy, Pharmacognosy, University of Innsbruck, Austria

Analytical sciences are steadily evolving, with new techniques like capillary electrophoresis (CE) and capillary electrochromatography (CEC) being reported frequently. They often claim to be advantageous in respect to separation efficiency and selectivity, but sometimes fail to convince in terms of practical use. In this presentation the audience is briefly introduced to theory and characteristics of CE and CEC, followed by several respective applications on natural products analysis conducted in our lab. They range from the determination of flavonoids and phenolic acids in Arnica montana (CE-UV) (1), over quinolizidine alkaloids in Lupinus species (CE-MS) (2), to adrenergic amines in Citrus aurantium (3) and naphthoquinones in Eleutherine americana (monolithic CEC) (4). For the latter a comparison to HPLC was attempted. It showed that a novel methacrylate-based monolithic stationary phase enabled the baseline separation of five markers (including eleutherin and isoeleutherin) in less than 11 min (HPLC: 22 min), and permitted their quantitative analysis in herbal material with the same precision (e.g. total naphthoquinones by CEC: $0.41 \%$, by HPLC: $0.45 \%)$. Only in respect to sensitivity CEC was less advantageous (limit of detection: $2-8 \mu \mathrm{g} / \mathrm{ml}$, compared to $0.4-0.8 \mu \mathrm{g} / \mathrm{ml}$ by HPLC), otherwise all validation criteria were met and comparable. This and the above mentioned examples indicate the practical applicability of $\mathrm{CE}$ and $\mathrm{CEC}$, and hopefully raise further interest in these "exotic" techniques.

References: (1) M. Ganzera, C. Egger, C. Zidorn, et. al., Anal. Chim. Acta., 614, 196-200, 2008. (2) M. Ganzera, A. Krüger, M. Wink, J. Pharm. Biomed. Anal., 53, 1231-1235, 2010. (3) E. Chizzali, I. Nischang, M. Ganzera, J. Sep. Sci., 34, 2301-2304, 2011. (4) M. Ganzera, I. Nischang, C. Siegl, et. al., Electrophoresis, 30, 3757-3763, 2009.

\section{STRUCTURE AND BIOACTIVITY OF 1 MG VATIPAROL BY SLIM TUBE NMR}

\section{() Ge Hui Ming, Tan Ren Xiang}

\section{School of Life Sciencs, Nanjing University, Nanjing 210093, China, e-mail: hmge@nju.edu.cn}

Bioactive natural products offer multiple opportunities for the discovery of novel chemical entities with potential pharmaceutical and agrochemical applications. But, it is increasingly difficult to determine the structure and bioactivity of novel natural compounds available only in minor or trace quantities (1). Vatiparol, a resveratrol trimer from Vatica parvifolia with an unprecedented carbon skeleton, showed selective inhibitory effect on the expression of monocyte chemoattractant protein-1 (MCP-1) (2). Of particular importance for the structure determination of this organic compound that was available only in trace amounts is our determination of the relative configuration and accurate conformation of vatiparol with RDC (residual dipolar coupling) enhanced NMR using only one milligram of the sample in a $1.7 \mathrm{~mm}$ NMR tube. Based on the NMR determined conforma- tion, the absolute configuration was elucidated with chiroptical methods (Figure).

In conclusion, the presented methodology and strategy will be generally useful for the determination of structure and bioactivity of novel natural compounds with limited availability.

References: (1) H.M.Ge, W.H. Yang, Y. Shen, N. Jiang, Z. K. Guo, Q. Luo, Q.Xu, J.Ma, R. X. Tan. Immunosuppressive Resveratrol Aneuploids from Hopea chinensis. Chem Eur. J, 2010, 16, 63386345. (2) H.M.Ge, H. Sun, N. Jiang, Y.H. Qin, H. Dou, T. Yan, Y. Y. Hou, C. Griesinger, R.X. Tan. Relative and Absolute Configuration of Vatiparol (1 mg): A Novel Anti-inflammatory Polyphenol. Chem - Eur. J., 2012, Published online: DOI: 10.1002/chem.201104078. 


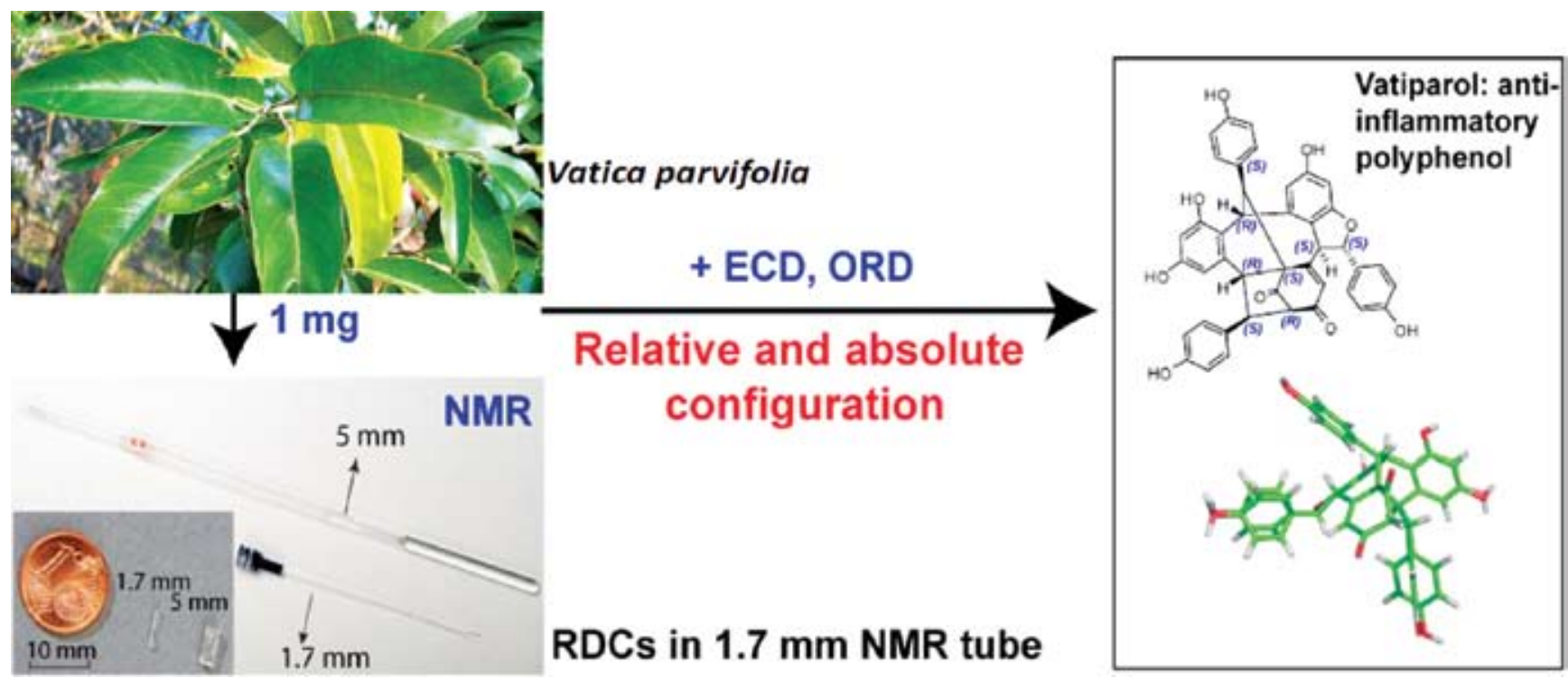

Figure. Structure determination of vatiparol. (ORD, optical rotatory dispersion; ECD, electronic circular dichroism)

\section{CRUDE AND ETHANOL EXTRACTS OF PROPOLIS AS NATURAL GROWTH PROMOTERS (NGPS) IN MEAT POULTRY PRODUCTION}

\section{(c) Gheisari Abbasali ${ }^{1}$, Ghalamkari Gholamreza ${ }^{1}$, Amini Hamid Reza $^{2}$, Shahrvand Shekofa ${ }^{2}$, Rezayat Ehsan ${ }^{2}$, Mohammadrezaei Mohammad $^{2}$}

${ }^{1}$ Department of Animal Science, Khorasgan Branch, Islamic Azad University, Isfahan, Iran ${ }^{2}$ Young Researchers Club, Khorasgan Branch, Islamic Azad University, Isfahan, Iran

This study was conducted to evaluate the effects of feeding different levels and sources of propolis substituted for Flavophospholipol as an antibiotic growth promoter on performance of broiler chickens in a completely randomized design. Five hundred and twenty days old broiler chicks (Ross 308) were divided into 40 experimental units of 13 chicks each. Each 4 groups were allocated to one of the ten dietary treatments, randomly. Dietary treatments were included control diet, diet containing $500 \mathrm{mg} / \mathrm{kg}$ of antibiotic Flavophospholipol, 4 diets containing different levels of 50, 100, 200 and $300 \mathrm{mg} / \mathrm{kg}$ ethanol extracts of propolis (EEP) and 4 diets containing 250, 500, 1000 and $2000 \mathrm{mg} / \mathrm{kg}$ of crude propolis. The Indices of performance were evaluated for each treatment during the experimental period (0-42 d of age). The results showed that daily weight gain and feed conversion ratio had no significantly affected by different dietary levels and sources of propolis compared to chickens fed antibiotic Flavophospholipol. The highest averages of body weight at $42 \mathrm{~d}$ of age $(2284 \mathrm{~g})$ and feed intake in total experimental period ( $100.4 \mathrm{~g} / \mathrm{bird} / \mathrm{d}$ ) assigned to chickens fed diet containing $100 \mathrm{mg} / \mathrm{kg}$ EEP. Totally, the results of this experiment showed that, similar to diet containing antibiotic growth promoter, feeding diets supplemented with $100 \mathrm{mg} / \mathrm{kg}$ EEP or $500 \mathrm{mg} / \mathrm{kg}$ crude propolis can improve performance of broiler chicks compared to control diet.

\section{LIFE WITH LARCH - ISOLATED ARABINOGALACTANS AND THEIR IMMUNOLOGICAL ACTIVITIES}

\section{(C) Göllner E. M.}

Pharmaceutical Institute, Department of Pharmaceutical Biology, University of Kiel, Gutenbergstra e 76, 24118 Kiel, Germany

The macromolecular larch arabinogalactan (LAG) is a highly branched polysaccharide consisting of a 1,3-linked galactan backbone with side-chains of 1,6-linked galactose and arabinose residues (1). LAG is an excellent source of dietary fiber and has been approved as such by the US Food and Drug 